\title{
Multiple Endocrine Neoplasia Type 4
}

National Cancer Institute

\section{Source}

National Cancer Institute. Multiple Endocrine Neoplasia Type 4. NCI Thesaurus. Code C157449.

An autosomal dominant tumor syndrome caused by germline CDKN1B mutations that result in a phenotype similar to that of multiple endocrine neoplasia type 1, characterized by endocrine neoplasms, particularly in the parathyroid glands, pituitary, and pancreas. (WHO 2017) 